
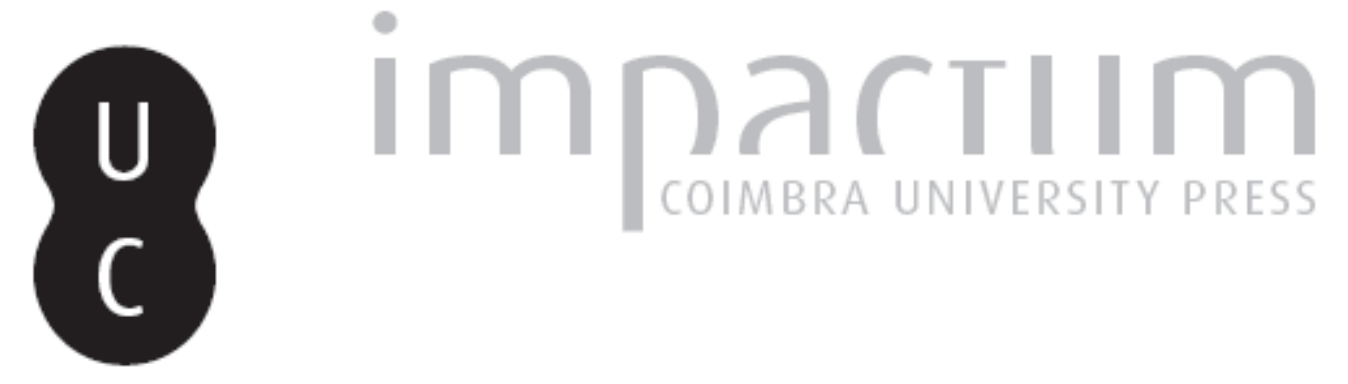

\title{
A actualização do sistema de indemnização nos acidentes de viação: uma reforma necessária?
}

Autor(es): $\quad$ Quintero, J.Alvarez; Luis, M. João Sales

Publicado por: Imprensa da Universidade de Coimbra

URL persistente:

URI:http://hdl.handle.net/10316.2/33074

DOI:

DOI:http://dx.doi.org/10.14195/1647-8630_18_1

Accessed : $\quad$ 26-Apr-2023 14:08:39

A navegação consulta e descarregamento dos títulos inseridos nas Bibliotecas Digitais UC Digitalis, UC Pombalina e UC Impactum, pressupõem a aceitação plena e sem reservas dos Termos e Condições de Uso destas Bibliotecas Digitais, disponíveis em https://digitalis.uc.pt/pt-pt/termos.

Conforme exposto nos referidos Termos e Condições de Uso, o descarregamento de títulos de acesso restrito requer uma licença válida de autorização devendo o utilizador aceder ao(s) documento(s) a partir de um endereço de IP da instituição detentora da supramencionada licença.

Ao utilizador é apenas permitido o descarregamento para uso pessoal, pelo que o emprego do(s) título(s) descarregado(s) para outro fim, designadamente comercial, carece de autorização do respetivo autor ou editor da obra.

Na medida em que todas as obras da UC Digitalis se encontram protegidas pelo Código do Direito de Autor e Direitos Conexos e demais legislação aplicável, toda a cópia, parcial ou total, deste documento, nos casos em que é legalmente admitida, deverá conter ou fazer-se acompanhar por este aviso.

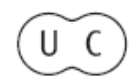




\title{
A actualização do sistema de indemnização nos acidentes de viação. Uma reforma necessária?
}

\author{
J.Alvarez Quintero' ${ }^{1}$, M. João Sales Luis ${ }^{2}$
}

Neste artigo, que teve por base as apresentações ${ }^{3}$ realizadas para divulgar o novo regime de indemnização ${ }^{4}$ nos acidentes de viação, tentaremos demonstrar que a reforma do sistema era necessária e oportuna. Não duvidamos que vai permitir indemnizar as vítimas de forma mais célere, e transparente, propiciando uma mais justa distribuição dos valores indemnizatórios, beneficiando tanto as vítimas com lesões mais graves como as de menores rendimentos.

Em nossa opinião, o novo sistema indemnizatório português adequa-se melhor à Resolução (75) 7 aprovada pelo Conselho de Ministros da União Europeia em $1975^{5}$, Resolução que define os princípios de compensação dos danos corporais no espaço comunitário e que, decorridos mais de 35 anos desde a sua aprovação, continua a ser de referência obrigatória nesta matéria.

Em conclusão, que nos permitimos adiantar, diremos que o novo regime ajudará a vencer o atraso histórico de Portugal na adaptação da legislação do seguro obrigatório às necessidades das vítimas de acidentes de viação.

\section{0 seguro obrigatório em Portugal}

O seguro obrigatório de responsabilidade civil automóvel foi instituído em Portugal em1979, pelo DL 408/79 de 25 de Setembro. Dinamarca, Finlândia

1 Administrador das Companhias de Seguros Fidelidade-Mundial , Império-Bonança e Multicare e Presidente da Comissão Técnica Automóvel da APS

2 Administradora da Companhia de Seguros Multicare e ex-Directora da Direcção de Sinistros Automóvel da Império-Bonança e Fidelidade-Mundial

$3 \quad 7^{\circ}$ Congresso Nacional de Medicina Legal, Tomar, 7-8 Novembro de 2008; Seminário Peopil, Porto, 3 Outubro de 2008 e Jornadas'08 da APS de 9 de Outubro de 2008

4 Decreto-Lei 291/2007 de 21 de Agosto; Portaria 377/2008 de 26 de Maio

5 Council of Europe. Committee of Ministers Resolution (75) 7 On compensation for physical injury or death adopted on 14 March 1975 at the 233erd meeting of the Minister's Deputies 
Suécia, Alemanha e o Reino Unido, entre outros, já o tinham feito antes da II Guerra Mundial. Em 1958 foi introduzido em França, e já nos anos 60 a Espanha (1968) e a Itália (1969) tinham seguido o exemplo.

Em 1980, pela primeira vez muitas famílias, das 2.262 vítimas mortais de acidentes de trânsito naquele ano $^{6}$, tiveram uma lei que lhes permitia reclamar a compensação dos danos sofridos a um devedor solvente. Circulavam já mais de 2.000.000 de veículos e o país apresentava rácios de sinistralidade rodoviária incomparavelmente piores do que outros países com legislações mais avançadas em matéria de protecção às vítimas.

Cinco anos depois, em 1985, pelo DL 522/85 de 31 de Dezembro, o seguro obrigatório passou a garantir capitais mínimos e foi alargado a todos os ocupantes do veículo que não tivessem relação familiar com o condutor, o proprietário ou o tomador do seguro.

Teremos de esperar mais de 20 anos para que os capitais mínimos do seguro obrigatório fossem actualizados e estabelecidas novas regras para simplificar e agilizar os processos de reclamação de danos e de indemnização. A directiva 2005/14/CE do Parlamento Europeu e do Conselho de 11 de Maio de 2005 serviu de base a este movimento de modernização.

\section{0 seguro obrigatório no direito comparado}

Esta inércia contrasta com a evolução da responsabilidade civil automóvel no direito comparado. Na verdade, a maioria dos países europeus tem adaptado o instituto de responsabilidade civil às características próprias da compensação de danos emergentes dos acidentes de viação, trilho que logo tem sido seguido para a cobertura de outros riscos próprios da sociedade actual.

A primeira característica, que consideramos própria da compensação de danos emergentes de acidentes de viação, é a transferência obrigatória do risco individual para o seguro, seja privado ou público. Esta transferência de responsabilidade é uma garantia para as vítimas de que receberão as indemnizações a que têm direito, ainda que arraste como consequência a anulação da penalização do lesante, implícita no instituto de responsabilidade civil, que deveria ver afectado o seu património pela indemnização devida à vítima (consequência idealmente vantajosa no plano da prevenção geral ou especial).

A segunda característica, consequência da anterior, reside na circunstância do custo das indemnizações ser um custo suportado pela comunidade de tomadores de seguro, comunidade que pela sua dimensão - praticamente todas as famílias portuguesas têm um ou mais veículos - o transforma

6 Direcção Geral de Viação. Observatório de Segurança Rodoviária 
num custo social: a soma das compensações devidas às vítimas não pode ultrapassar a capacidade da sociedade as pagar, via prémios de seguros ou cotizações obrigatórias.

A terceira característica, é a proliferação das situações de risco criado pela circulação maciça de veículos, para todos os utentes das vias públicas e, em particular, para os mais débeis - os peões e os ciclistas - e, em consequência, a multiplicação de prejuízos que carecem de reparação, sendo necessário estabelecer procedimentos adequados para o conseguir.

As principais linhas de evolução no direito comparado podem agrupar-se em três grandes categorias: as que melhor visam proteger as vítimas do risco criado pela circulação automóvel - tornando a indemnização obrigatória -, as que têm por objectivo padronizar as indemnizações e finalmente as que procuram agilizar os procedimentos de reclamação e de indemnização dos danos, em particular dos danos pessoais, sendo poucas as situações em que estas grandes categorias não estão interligadas.

\subsection{A indemnização obrigatória}

Quanto ás soluções que visam proteger melhor as vítimas do risco criado pela circulação automóvel, desde logo, a Finlândia e outros países nórdicos, nos anos 60, adoptaram o princípio de responsabilidade objectiva. Segundo este princípio, sempre que exista nexo causal entre as lesões e o acidente, a vítima tem de ser indemnizada, mesmo que o condutor do veículo não tenha culpa ou que a própria vítima tenha contribuído para a ocorrência do acidente. Este sistema, também baptizado de "non-fault" vigora hoje em numerosas legislações, dentro e fora de Europa, sendo o mais habitual a sua aplicação exclusiva aos danos corporais.

A Loi Badinter, em vigor desde $1985^{7}$ para os acidentes de viação ocorridos em França, exime de culpa as vitimas não condutores (ocupantes, peões e ciclistas), excepto nos casos de falta de excepcional gravidade.

Outro exemplo, mais próximo, é o do regime que vigora em Espanha desde 1995, data em que foi publicada uma nova lei para a responsabilidade civil resultante da circulação de veículos a motor ${ }^{8}$. A lei atribui ao condutor do veículo a responsabilidade pelos danos causados às pessoas em virtude do risco criado pela condução do mesmo ${ }^{9}$, sendo que esta responsabilidade

Loi du 5 juillet 1985

8 Ley 30/1995 del 8 de Diciembre de Ordenación y Supervisión de los Seguros Privados

9 El conductor de vehículos a motor es responsable, en virtud del riesgo creado por la conducción del mismo, de los daños causados a las personas o en los bienes con motivo de la circulación. Título I, Capítulo I, Artigo 1 de la Ley 30/1995 
pode ser afastada quando o condutor prove que os danos foram devidos exclusivamente a conduta (negligente ou dolosa) da vítima.

Porém, a exclusão de cobertura da vítima nos casos em que agiu com culpa exclusiva, como previsto no direito espanhol e francês, para citar apenas dois exemplos, não é pacífica em termos do direito comunitário, pelo menos nos danos causados aos ocupantes do veículo. Com efeito, o Tribunal de Justiça Europeu estabeleceu, que o artigo $1^{\circ}$ da Terceira Directiva, se opõe a uma regulamentação nacional que permita excluir ou limitar de modo desproporcionado - com fundamento na contribuição de um passageiro para a produção do seu dano -, a indemnização suportada pelo seguro automóvel obrigatório $^{10}$. Acresce que a Directiva se opõe, também, a qualquer legislação nacional nos termos da qual o seguro obrigatório de responsabilidade civil automóvel pudesse não cobrir a responsabilidade por danos corporais causados a pessoas que viajassem numa zona do veículo automóvel não concebida, nem construída, para o transporte de passageiros ${ }^{11}$.

Nesta mesma linha de defesa das vítimas de acidentes de trânsito, o Tribunal Europeu condenou o Estado Português ${ }^{12}$ pela existência, na Lei Civil, de limites para a responsabilidade pelo risco inferiores aos capitais mínimos obrigatórios.

Ora, a actualização dos limites de responsabilidade pelo risco em Portugal, implicou, na prática, uma quase inversão do ónus da prova (pelo menos no caso das vitimas desprotegidas, como os peões) na medida em que a seguradora apenas pode recusar a indemnização quando possa provar a culpa da vítima, (se não provar a culpa do peão, o acidente acaba por ser resolvido com base no risco, sem outros limites que não os do seguro, sendo pacifico o entendimento de que o peão não cria risco à circulação)

Em síntese, parece poder concluir-se que as indemnizações devidas pelo seguro obrigatório automóvel têm vindo progressivamente a ser autonomizadas do instituto clássico da responsabilidade civil, efectuando-se essa autonomização seja pelo lado da exigência de efectiva responsabilidade para a eficácia da cobertura, seja pela criação de soluções que alteram as regras clássicas de prova, recorrendo a mecanismos de inversão do ónus da prova.

\subsection{A padronização das indemnizações}

Relativamente à quantificação dos danos, a generalidade dos países mantém como princípio básico a reparação integral do dano (assim o prevê a

\footnotetext{
10 Caso Candolin (processo C-537/03) Tribunal de Justiça Europeu

11 Caso Farrel (processo C-356-05)

12 Caso V. Mendes Ferreira e C. Delgado Correia Figueira (processo C-348/98)
} 
Resolução do Comité de Ministros do Conselho de Europa atrás referida ${ }^{13}$ ) e o artigo $562^{\circ}$ do Código Civil Português estabelece o mesmo princípio: "quem estiver obrigado a reparar um dano deve reconstituir a situação que existiria se não se tivesse verificado o evento que obriga à reparação”.

A reparação integral, seguindo os critérios de AVV. Marco Bona ${ }^{14}$ significa: a) ter em consideração todos os danos económicos e não económicos, assim como as alterações à saúde e à vida de cada vítima; b) que a compensação seja proporcional aos danos sofridos pela vitima e c) que lesões semelhantes sejam compensadas com indemnizações semelhantes e diferentes lesões sejam indemnizadas de forma diversa.

A realidade, porém, mostra grandes discrepâncias nos valores indemnizatórios nos diferentes países da União Europeia, diferenças que não se justificam pelos níveis de riqueza de cada país (gráfico $\mathrm{n}^{\circ} 1^{15}$ ), mas antes, pela forma diversa como são avaliados os prejuízos económicos futuros, e, ainda, pelas diferenças na indemnização dos danos não patrimoniais bem como das diferenças que decorrem de distinta interligação entre o seguro e os sistemas de segurança social e/ou de saúde. Outros factores também influenciam os resultados, como os procedimentos de avaliação das sequelas, os procedimentos de reclamação, etc.

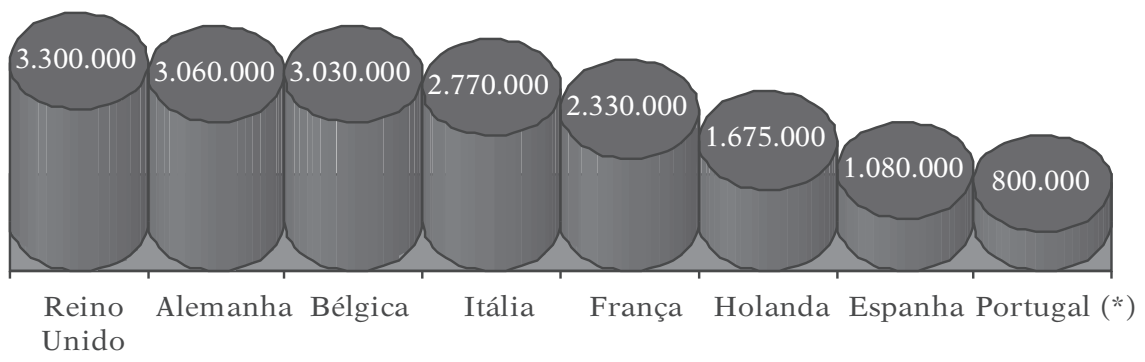

Gráfico 1. Custos indemnizados pela seguradora a um tetraplégico (C6-C7) de 25 anos e $30.000 €$ de rendimento anual e despesas médicas passadas de igual valor em todos os países

13 Subject to the rules relating to liability, the person who has suffered damage has the right to compensation for this damage suffered so that he is restored to a situation as near as possible to that in which he would have been if the act for which compensation is claimed had not occurred. General Provisions I-1 Principles Related to Compensation for Damage in the case of Physical Injury and Death

14 AVV. Marco Bona Public Hearing on Road Traffic Accidents en the European Parliament. Committee on Legal Affairs. 19 March 2007

15 CEA/AREDOC L'indemnisation du dommage corporel en Europe. Résultats d'une enquête effectuée à partir de cas concrets. Donnés 2003.

* Portugal. Informação própria 
A diferença de valores indemnizatórios não se circunscreve ás diferenças de país para país - o que seria compreensível e, até certo ponto, justificável sendo frequente observar fortes diferenças, dentro do mesmo país, de região para região ou até de tribunal para tribunal, pondo em causa o principio de igualdade de tratamento entre as vitimas.

O movimento, que actualmente existe na Europa, em favor duma maior harmonização das indemnizações é consequência, em primeiro lugar, do aumento de sinistros com vítimas que circulam entre diferentes estados membros e das obrigações impostas pela $4^{\mathrm{a}}$ Directiva $^{16}$ para a regularização célere dos mesmos. Mas também resulta do próprio processo de harmonização "nacional", na medida em que este só é possível, se forem estabelecidas referências de indemnização. Referências que terão de surgir em dois âmbitos: no âmbito da perícia médica, em particular na procura de critérios comuns na avaliação dos danos à integridade física e psíquica, e no âmbito judicial e extrajudicial, no que concerne à determinação de valores orientadores para a fixação das indemnizações, nomeadamente às de carácter imaterial ou não patrimonial.

Relativamente à avaliação médica, os países de tradição "latina" - França, Bélgica, Itália, Espanha e Portugal - adoptaram tabelas com escalas de 1 a 100 para medir a gravidade das sequelas e as repercussões nas actividades da vida diária. A Tabela Europeia ${ }^{17}$, que vigora desde Janeiro de 2006 para a avaliação pericial dos funcionários comunitários, e que tem como objectivo uma futura harmonização europeia, resulta destas experiências. Cabe esperar que as futuras actualizações das tabelas de cada um dos países da UE adoptem, ou se aproximem, da Tabela Europeia, como já foi feito em Portugal com a publicação da Tabela de Avaliação de Incapacidades Permanentes em Direito Civil ${ }^{18}$.

Relativamente ao regime compensatório, a dispersão de modelos é maior, mesmo entre países de tradições legais próximas. Espanha e Itália adoptaram, por lei, tabelas de valores de indemnização - neste último país, apenas para as pequenas incapacidades (até 10 pontos de Incapacidade Permanente Parcial) - que englobam danos económicos e não económicos, atribuindo um valor indemnizatório a cada ponto, valor que cresce com a gravidade e decresce com a idade. Em França, Bélgica ou Itália os danos não económicos são indemnizados com referência à jurisprudência dos tribunais, que pode

\footnotetext{
16 Directiva 2000/26/CE do Parlamento e do Conselho de 16 de Maio

17 Guide barème d'evaluation médicale des atteintes à l'integrité physique e psychique. Ed Anthemis

18 Decreto-Lei no 352/2007 de 23 de Outubro
} 
variar de região para região. No Reino Unido o Judicial Studies Board ${ }^{19}$ publica regularmente "guidelines" para o cálculo dos danos não patrimoniais. Na Irlanda, funciona desde Julho de 2004, um órgão independente (PIAB-Personal Injuries Assessment Board) ${ }^{20}$ para a avaliação dos danos não patrimoniais, o que é feito com referência à Tarifa Pública de Danos que especifica os valores máximos e mínimos para as sequelas mais frequentes. Finalmente, nos países nórdicos, e, em especial, na Finlândia, todo o ênfase é posto na reabilitação da vítima, sendo as indemnizações por danos não económicos marginais ${ }^{21}$.

Desta sumária exposição, pode apreciar-se a diversidade de soluções existentes, porém, também é possível vislumbrar pontos de convergência, nomeadamente na atribuição, às sequelas mais frequentes, de valores de compensação de danos não económicos, sejam estes calculados por referência a uma tarifa pública de danos ou multiplicando os pontos resultantes das Tabelas Médicas pelo valor do ponto fixado nas Tabelas de Indemnização.

De salientar, como logo teremos oportunidade de detalhar, que o modelo que vigora em Portugal, depois da transposição da $5^{\text {a }}$ Directiva, está em linha com as tendências centrais antes referidas, sendo, que os valores económicos resultantes mostram uma convergência efectiva com os valores praticados em países de maior riqueza.

\subsection{A Proposta Razoável}

Finalmente, e no que diz respeito ao terceiro pilar de evolução - o da procura de procedimentos que permitam agilizar a reclamação e indemnização dos danos - a solução mais generalizada, e agora harmonizada a nível comunitário pela $5^{\text {a }}$ Directiva ${ }^{22}$, reside no estabelecimento de prazos máximos de resposta à reclamação, assim como, na formulação, dentro destes prazos, de uma Proposta Razoável ou de uma Resposta Fundamentada.

Quer os prazos - noventa dias, a contar da data da reclamação,- quer as figuras da proposta razoável e da resposta fundamentada, vigoram para os sinistros ao abrigo da $4^{\mathrm{a}}$ Directiva, os sinistros com vitimas de diferentes países comunitários, desde 2003.

Os procedimentos de oferta razoável e resposta fundamentada foram transpostos para os direitos nacionais, nalguns países, sem alterações, com alterações significativas, noutros. Na Itália, por exemplo, o prazo foi reduzido de 90 para 60 dias nos sinistros de danos materiais. Em Espanha foram

19 www.jsboard.co.uk/publications.htm

20 www.injuriesboard.ie/eng/Forms_and_Publications/Book_of_Quantum

21 Janne Jumppanen, Finland's Streamlinead Approach. Partner Re 2008

22 Directiva $n^{\circ}$ 2005/14/CE, do Parlamento Europeu e do Conselho, de 11 de Maio 
acrescentados deveres de informação, até agora inexistentes, nomeadamente o envio de documentos necessários à formulação da proposta razoável e da resposta fundamentada (neste último caso, como exemplo, retenha-se que quando a fundamentação residir na impossibilidade de quantificação do dano, o devedor terá de actualizar a informação todos os meses). Portugal, como teremos oportunidade de explicitar melhor, foi o país que introduziu mais obrigações adicionais às já previstas na norma comunitária.

Apesar do exposto, podendo afirmar-se que embora subsistam diferenças substanciais na regularização de sinistros no domínio judicial, as diferenças tendem a desaparecer ou, pelo menos, a serem mais mitigadas, no plano extrajudicial, sendo que os novos procedimentos instituídos vão ter impacto profundo nas práticas indemnizatórias de cada país, estimulando a sua convergência.

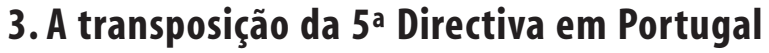

A transposição da $5^{\text {a }}$ directiva para o direito interno, efectuada pelo Decreto-Lei 291/2007 de 21 de Agosto mudou o paradigma indemnizatório, atribuindo às vítimas novos direitos e impondo às seguradoras exigentes obrigações, quando comparadas com as vigentes noutros normativos.

Assim, os prazos de reposta à reclamação são hoje de 30 dias úteis para os sinistros com danos materiais - reduzidos a 15 caso os dois condutores tenham assinado a Declaração Amigável de Acidentes Automóvel - e contados desde a data da participação do acidente. Acrescem para as seguradoras outras obrigações, como a de contactar o lesado em 2 dias úteis, concluir a peritagem nos 8 dias úteis seguintes, etc... etc.... Para os danos corporais o prazo de reposta à reclamação é de 45 dias corridos, embora, neste caso, o prazo comece a contar desde a data em que o lesado efectua a reclamação.

Nos termos da lei, o cumprimento de todos os prazos e obrigações é controlado exaustivamente, pelo Instituto de Seguros de Portugal, através da conferência de ficheiros, enviados pelas seguradoras, com informação sobre todos os sinistros encerrados, sendo que o incumprimento de qualquer prazo legal é punido com coima que vai de $3.000 €$ a $44.890 €$.

Os deveres de informação das seguradoras são agora especialmente alargados, sejam os relativos à informação comum (os procedimentos de gestão de sinistros, os prazos de regularização, as convenções e arbitragens a que aderiu, etc.) sejam os específicos de cada sinistro (relatório de peritagem, exame médico, exames complementares, etc.). 
Este vasto conjunto de imposições mudou a prática habitual de gestão de sinistros das seguradoras em três aspectos fundamentais: maior diligência, transparência absoluta e fiscalização exaustiva.

O novo paradigma de gestão representa uma significativa ruptura com o tradicional modo de gestão dos sinistros, especialmente daqueles com danos corporais, caracterizado como estava pela lentidão, opacidade e escassa supervisão. Retenha-se que a demora média para regularizar um sinistro é de dois anos e, caso o processo seja tramitado em Tribunal, esse tempo médio é aumentado para mais de cinco anos. Retenha-se, ainda, que mais de metade dos sinistros contenciosos terminam por acordo na semana do julgamento, ou nas semanas imediatamente precedentes, facto a que não é alheio tanto a opacidade que domina a relação entre segurador, lesado e os seus representantes, como o momento tardio em que se verifica a perícia médico-legal.

No cenário em que vivíamos (e do qual ainda não saímos verdadeiramente) a disparidade dos valores de indemnização em situações semelhantes é enorme, seja entre sinistros regularizados por acordo judicial ou extrajudicial, seja entre sinistros indemnizados por sentença, em ambos os casos em claro e grave incumprimento do principio jurídico de tratar igual o que é igual e diferente o que é diferente.

$\mathrm{Na}$ origem destas diferenças está, sobretudo, a prática judicial de considerar alguns danos de natureza não patrimonial como danos patrimoniais e, de indemnizá-los como tal, considerando que toda e qualquer incapacidade funcional tem repercussões na capacidade de ganho. Exemplo desta abordagem é o aresto do $\mathrm{STJ}^{23}$ que considerou que a disfunção psicossexual corresponde à perturbação da inibição da excitação sexual e inibição do orgasmo que se traduz numa "incapacidade funcional" da vítima, constituindo um "dano patrimonial”.

Considerado o rendimento como pedra basilar do cálculo da indemnização, não admira que vitimas da mesma idade e com igual sequela funcional, com os sofrimentos físicos e psíquicos que ela comporta, tenham indemnizações diferentes, proporcionais aos respectivos rendimentos, em clara contradição com a Resolução (75) 7 do Comité de Ministros do Conselho Europeu, que estabelece que as dores físicas e os sofrimentos psíquicos devem ser compensados na base da sua severidade e duração, independentemente da situação financeira da vítima ${ }^{24}$.

23 STJ (SOUSA INÊS) por ac de 28 de Outubro de 1999

24 Compensation is to be paid for physical pain and mental suffering on the basis of their severity and duration. Compensation is to be calculated without regard to the victim's financial situation. Provision 12 of Principles Related to Compensation for Damage in the case of Physical Injury and Death. 


\subsection{A formulação da Proposta Razoável no caso dos danos corporais}

Sobre esta matéria, inovadoramente, o Decreto-lei no 291/2007 de 21 de Agosto estabelece que uma proposta é razoável quanto tiver sido efectuada nos termos substanciais e procedimentos previstos no sistema de avaliação e valorização dos danos corporais por utilização da Tabela Indicativa para Avaliação de Incapacidades Permanentes em Direito Civil e por recurso aos critérios e valores orientadores constantes de portaria aprovada pelos Ministérios das Finanças e Administração Pública e da Justiça ${ }^{25}$.

$\mathrm{Na}$ exposição de motivos deste último diploma ${ }^{26}$, consta que "o regime relativo aos prazos e as regras de proposta razoável (...) exige o apoio de normativos específicos que evidenciem, com objectividade, a transparência e justiça do modelo no seu conjunto e sejam aptos a facilitar a tarefa de quem está obrigado a reparar o dano e sujeito a penalizações, aliás significativas, pelo incumprimento de prazos ou quando for declarada judicialmente a falta de razoabilidade na proposta indemnizatória".

Com efeito, a principal característica deste diploma é a definição de critérios e valores orientadores para as seguradoras, cabendo recurso aos Tribunais, caso o lesado considere que a indemnização proposta seja considerada inadequada ou insuficiente.

A Portaria 377/2008 veio assim definir quais os danos indemnizáveis em caso de sinistro com dano corporal, estabelecendo fórmulas de cálculo para a determinação dos danos patrimoniais futuros e padronizando tanto os danos morais como o dano biológico ou dano à integridade física e psíquica.

\subsubsection{0s danos indemnizáveis em caso de morte na Portaria 377/2008}

Os danos indemnizáveis de natureza não patrimonial são agrupados em três categorias: a violação do direito à vida, o dano moral da própria vitima e o dano moral dos herdeiros, definidos estes com respeito pelas regras estabelecidas no Código Civil.

Adiante-se, desde já, que a violação do direito à vida é um conceito indemnizatório específico do direito português. Já a STJ (BERNANRDEZ DE MIRANDA) de 17 de Março de 1971 afirmava que a perda do direito à vida constitui um dano não patrimonial autónomo, que deve ser pago aos herdeiros da vítima ${ }^{27}$. Na Portaria os valores da compensação para este dano

\footnotetext{
25 Artigo $39^{\circ} \mathrm{n}^{\circ} 3$ e 5

26 Portaria 377/2008 de 25 de Maio

27 Armando Braga.A Reparação do Dano Corporal na Responsabilidade Civil Extracontratual. Ed. Almedina. pag 182
} 
estão escalonados em função da esperança de vida, alcançando o valor máximo de $60.000 €^{28}$ para vítimas menores de 25 anos de idade ${ }^{29}$.

Acresce a este dano, de natureza não patrimonial, o dano moral da própria vitima $^{30}$. Os valores admitidos na Portaria, neste caso, variam em função da duração e intensidade da "antevisão" da morte, com um valor máximo de $10.500 €$, caso o sofrimento e antevisão da morte sejam de excepcional intensidade.

A terceira e última categoria dos danos não patrimoniais é o dano moral dos herdeiros ${ }^{31}$. Neste caso os valores indemnizáveis são graduados em função da proximidade do parentesco (cônjuge, filho, neto, irmão), da idade dos filhos e da duração da união matrimonial, quanto ao dano moral do cônjuge.

O legislador tabelou, ainda, a indemnização por Perda de Feto, já consagrada em muitas decisões judiciais, graduando-a em função do tempo de gravidez e da existência de outros filhos.

Para diferenciar as situações de excepcional gravidade (perda de um filho único, perda de todos os filhos no mesmo acidente, perda de ambos os progenitores, etc) o legislador optou por aplicar majorações às indemnizações base fixadas para os danos não patrimoniais,

Relativamente aos danos de natureza patrimonial, os de maior relevância em termos indemnizatórios, são os que resultam das perdas de rendimentos futuros daqueles que, nos termos da lei, podiam exigir alimentos à vítima ${ }^{32}$. Para este efeito, considerou-se que os rendimentos (fiscalmente provados), líquidos dos gastos que a vitima suportaria consigo própria, crescerão à taxa de $2 \%$, até aos 70 anos, sendo por sua vez actualizados à taxa nominal de 5\% (ambas as taxas, como todos os valores indemnizatórios previstos na Portaria, passíveis de revisão anual). A fórmula financeira, embora idêntica à utilizada pelo Tribunal da Relação de Coimbra, reveste-se de alguma complexidade para os não especialistas, pelo que na Portaria figuram os factores financeiros calculados para os prazos de 1 a 60. O prazo é exactamente o número de anos de vida activa que ainda seria expectável para a vítima. Assim sendo, o valor da indemnização i.e. o dano patrimonial futuro obtém-se multiplicando

28 A seguir expõem-se exemplos de indemnizações recentes no Supremo Tribunal de Justiça e o respectivo limite na Portaria 377/2008: STJ (2152-08) de 23 de Junho de 2008: 60.000€60.000€; STJ (3459-07) de 30-12-2007: 50.000€-60.000€; STJ (08B1841) de 19-06-2008: 60.000€-60.000€;STJ (08A1853) de 10-07-2008: 50.000€-40.000€; STJ (08B2989) de 30-102008: $60.000 €-60.000 € ; S T J ~(08 B 726)$ de 08-05-2008: 28.000€-42.000€ (neste último caso a vítima teve $30 \%$ de responsabilidade na ocorrência do acidente)

29 Anexo II (C) da Portaria 377/2008

30 Anexo II (D) e aplicação da majoração prevista no quadro B. Portaria 377/2008

31 Anexos II A e B da Portaria 277/2008

32 Anexo III da Portaria 377/2008 
o rendimento anual perdido pelo factor financeiro relativo ao prazo " $\mathrm{n}$ "33 correspondente.

Já os gastos com o próprio são graduados em função do agregado familiar que dependia da vítima, podendo variar em função do rendimento do cônjuge sobrevivo e da idade dos filhos. O diploma introduz, neste ponto, maior discriminação de valores do habitualmente praticado pelos tribunais ${ }^{34}$. É indubitável que estes factores correctores, quando majorem as indemnizações, não levantem nenhuma objecção e sejam amplamente admitidos nos tribunais. Maiores dificuldades apresentam os factores de redução. Ora bem, uns não podem existir sem os outros, e naturalmente ambos têm de ser aplicados ponderando as circunstâncias que visam avaliar e não de uma forma automática.

No âmbito patrimonial encontram-se ainda as perdas salariais da vítima decorrentes de incapacidade temporária desde a data do acidente até à data do óbito e as despesas de tratamento, funeral, etc., que forem provadas.

As indemnizações resultantes dos critérios anteriores à publicação da Portaria já atingiam valores comparáveis com os praticados em França ou Espanha, como se pode observar nos gráficos 2 e $3^{35}$.

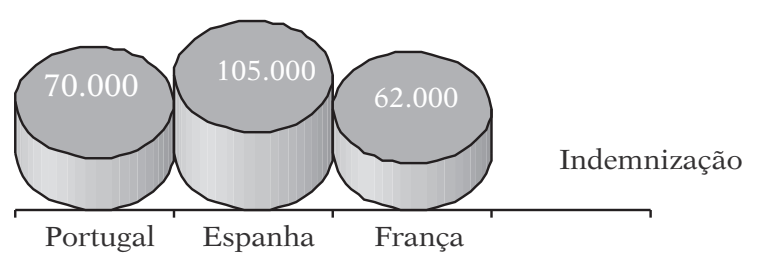

Gráfico 2. Criança 5 anos de idade (pai, mãe e irmão de 8 anos, sem avós) não inclui despesas de funeral

33 O diploma não especifica o que representa o termo "n" utilizado na fórmula. "n" é o prazo i.e. número de anos de vida activa expectável ou seja o número de anos decorridos entre a data definida para inicio da pensão e a data em que a vitima atingiria os 70 anos

34 O critério mais habitual é considerar que $1 / 3$ do rendimento é consumido com o próprio e o restante com o agregado familiar com independência de quem angaria os rendimentos e de qual a composição do agregado familiar

35 Estimativa própria com base nos critérios seguidos na seguradora para provisionar os sinistros em 2007 


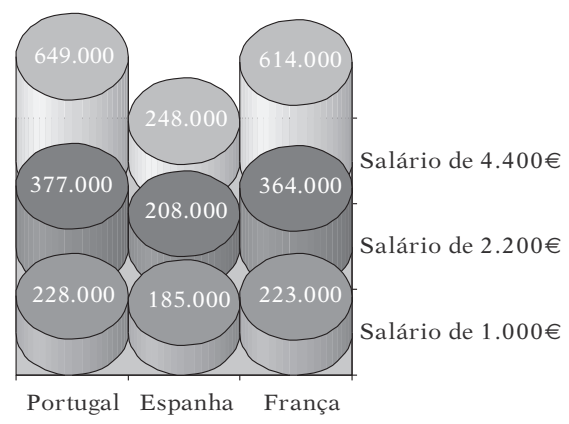

Gráfico 3. Homem de 40 anos, com mulher e 2 filhos de 10 e 15 anos

Porém, as indemnizações por morte vão aumentar significativamente, com a aplicação dos valores e critérios previstos na Portaria, por duas ordens de razões: os valores dela resultantes estão em linha com os mais elevados praticados nos tribunais e estes, por sua vez, ultrapassam largamente os indemnizados por acordo extrajudicial, tendo sido, tendencialmente, abolidas as diferenças entre as indemnizações praticadas nestes dois planos. Quanto à primeira afirmação é elucidativo o comentário do STJ (MARIA DE GRAÇA GOUVEIA) ${ }^{36}$ "de resto mostram-se respeitados os critérios e valores orientadores da "proposta razoável de indemnização" em acidente de viação definidos na Portaria $n^{\circ}$ 377/08 de 26 de Maio (anexo II-A) o que é demonstrativo da sua justeza".

Como se pode observar no gráfico $4^{37}$, na última década os valores médios de indemnização triplicaram, o que associado ao aumento acima referido permite afirmar que as indemnizações, outrora consideradas miserabilistas, têm vindo a acentuar a sua convergência para com os valores praticados na Europa.

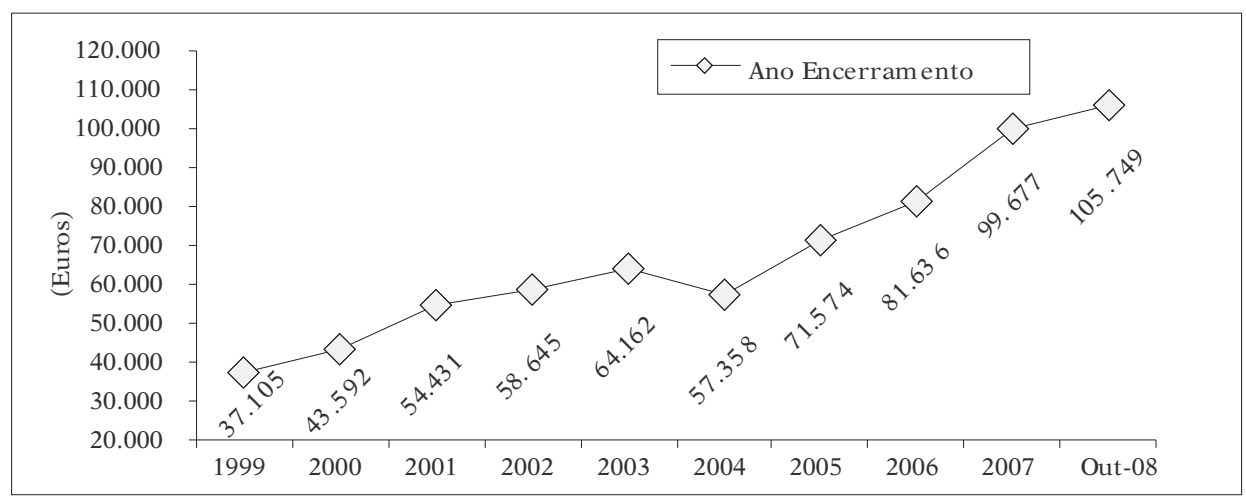

\section{Gráfico 4}

36 STJ 2152/08-5 de 24-06-2008

37 Custo médio dos sinistros encerrados pela Companhia de Seguros Império-Bonança 


\subsubsection{0s danos indemnizáveis em caso de outros danos corporais na Portaria 377/2008}

Também aqui temos de distinguir entre os danos de natureza não patrimonial e patrimonial mas, também, inovadoramente, afastarmo-nos de uma visão redutora da pessoa humana, admitido que o dano corporal tem dignidade para ser indemnizado como dano a se, ou seja, com independência do dano patrimonial e do dano não patrimonial que possa ocasionar.

No que aos danos patrimoniais respeita, e relativamente aos danos futuros nas situações de incapacidade permanente absoluta ${ }^{38}$, a Portaria, tal como nos casos de morte, considera que os rendimentos (fiscalmente provados) crescerão à taxa de $2 \%$, até aos 70 anos, sendo por sua vez actualizados à taxa nominal de $5 \%$. Para a incapacidade permanente absoluta para a profissão habitual, sem possibilidade de reconversão dentro da sua área de formação técnico profissional, o capital anterior é reduzido em 1/3 (por se considerar que a vitima continua apta a poder angariar rendimentos, não devendo ser incentivada a desistir de o fazer). Já quando é possível a reconversão a proposta indemnizatória corresponde a quatro anos de rendimentos líquidos (incentivando-se a efectiva reconversão profissional do lesado por forma a promover a sua efectiva reinserção social). A fórmula de cálculo do dano patrimonial futuro é idêntica à utilizada nos casos de morte e como tal aplicam-se-lhe os mesmos comentários.

$\mathrm{O}$ dano pela ofensa à integridade física e psíquica (dano biológico ${ }^{39} \mathrm{de}$ que resulte ou não perda de capacidade de ganho, é determinado, por peritos médicos devidamente qualificados ${ }^{40}$, segundo a Tabela Nacional para Avaliação de Incapacidades Permanentes em Direito Civil.

Embora seja possível encontrar com relativa frequência sentenças e acórdãos que se referem a este dano como dano "a se", carecendo de tutela jurídica autónoma, a forma como a Portaria quantifica a indemnização é verdadeiramente inovadora.

Na verdade, o método habitualmente utilizado, de multiplicar o coeficiente de incapacidade pelo salário liquido, isto é, de aplicar fórmulas de cálculo de danos patrimoniais a danos que revestem distinta natureza, tinha o efeito perverso de indemnizar as mesmas limitações funcionais para a vida diária dos lesados em função dos seus diferentes rendimentos. O exemplo seguinte ilustra bem esta afirmação: Imaginemos dois lesados da mesma idade que

38 Anexo III da Portaria 377/2008

39 Anexo IV da Portaria 377/2008

40 (...) esta nova Tabela Nacional para o direito civil destina-se a ser utilizada exclusivamente por médicos especialistas em medicina legal ou por especialistas médicos de outras áreas com específica competência na avaliação do dano corporal (...) Decreto-Lei No 352/2007 de 23 de Outubro 
sofrem os dois, em consequência de um acidente viação, de disfunção eréctil ${ }^{41}$. Imaginemos que um deles é pedreiro e ganha o salário mínimo e que o outro, empregado numa instituição financeira, ganha 2.250 /mês. Justificar-se-ia que o segundo receba uma indemnização cinco vezes superior só pelo facto do seu ordenado ser cinco vezes maior? Será que o pedreiro tem menor direito a uma vida sexual normal, a fundar uma família e ter filhos do que o empregado da instituição financeira? Aliás, este último, pela sua posição económica e social, pode, muito provavelmente, aceder, com maior facilidade, a soluções alternativas para mitigar a sua disfunção. Acresce que justificar, neste caso, a diferença nos valores indemnizados pelos esforços acrescidos seria, no mínimo, caricato. O direito à saúde, ou à integridade física, é igual para todos os seres humanos e deve ser autónomo e independente do nível de rendimento e da situação financeira da vítima. Aliás este tem sido o entendimento unânime dos tribunais atribuindo um valor à vida igual para todos, considerando apenas como elemento diferenciador a idade da vítima.

$\mathrm{O}$ tratamento desigual para iguais sequelas, que resulta dos critérios tradicionalmente seguidos pelos tribunais portugueses, está em contradição com os princípios e práticas seguidos pelos mesmos tribunais na indemnização dos danos não patrimoniais nas mortes, assim como com os princípios comuns a todos os países da União Europeia, conforme já referido. Certo é, que o critério adoptado tem sido útil para indemnizar valores mais elevados dos que resultariam da aplicação de critérios de equidade delimitados pelos valores arbitrados para o direito à vida. Com efeito, se o bem supremo é a própria vida, qualquer perda parcelar da mesma teria de ser indemnizada aquém daquele valor. Naturalmente esta afirmação seria inatacável se o destinatário da indemnização fosse o próprio, se fosse ele a escolher entre viver e não viver. Não é por acaso que este conceito não se encontra noutros sistemas compensatórios, que apenas indemnizam directamente os familiares da vítima pela dor e o sofrimento criado pela perda de um ser querido e não por um direito da própria vitima ${ }^{42}$. A jurisprudência tem ultrapassado aquela contradição considerando que as limitações funcionais para a vida diária têm consequências semelhantes para a vida laboral, não obstante “ ... não se ter provado que o autor haja passado a receber um vencimento mensal inferior... mas passa a ter de distender um esforço físico e psíquico, suplementar, em

${ }^{41}$ A Tabela de Avaliação de Incapacidades Permanentes em Direito Civil atribui à disfunção eréctil uma valorização em pontos entre 5 e 15 em função da avaliação clínica e do resultado dos exames complementares de diagnóstico

42 Acerca da titularidade do direito à indemnização pela ofensa ao direito à vida sugere-se a consulta de A Reparação do Dano Corporal na Responsabilidade Civil Extracontratual. Autor Armando Braga. Ed. Almedina. pag 182 e seguintes 
relação ao que acontecia, antes do acidente...." ${ }^{43}$. Isto é, as sequelas exigem esforços adicionais que são avaliados tendo como base a presunção de que existe perda salarial, seguindo a lógica das indemnizações dos Acidentes de Trabalho.

Mas a consequência mais perversa desta lógica indemnizatória é discriminar os que sofrem perdas efectivas de rendimentos dos que não sofrem, bem como penalizar os trabalhadores menos qualificados dos mais qualificados, sendo os primeiros os que provavelmente maiores dificuldades vão encontrar no seu futuro profissional.

No gráfico 5 mostram-se alguns exemplos dos desequilíbrios entre os montantes indemnizatórios e as gravidades das lesões.

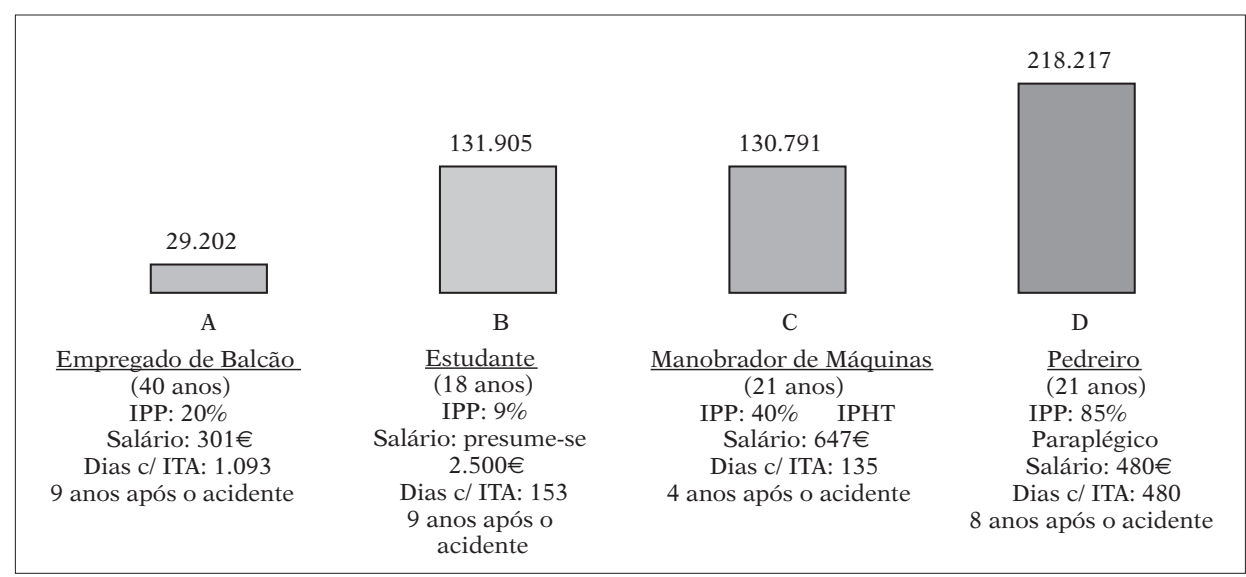

Gráfico 5. Incapacitados regularizados por sentença judicial ${ }^{44}$

Foi perante este estado de coisas que levou o legislador da Portaria a procurar uma nova via que consagrasse o princípio de igualdade - que deve nortear as indemnizações de natureza não económica.Com este intuito adoptou a Retribuição Mínima Mensal Garantida (RMMG) ou, mais exactamente, múltiplos desta, em substituição do salário individual do lesado, para determinar o valor a indemnizar por cada ponto de incapacidade, obtendo, assim, uma base de referência socialmente mais equitativa para transformar em dinheiro o que "a se" não tem valor monetário. Este racional está presente em praticamente todos os valores de danos que não revistam natureza patrimonial, previstos na norma.

43 STJ (04B2084) de $4-11-2003$

44 Repara-se que apenas nos exemplos $\mathrm{C}$ e $\mathrm{D}$ foram provados danos patrimoniais futuros. $\mathrm{O}$ manobrador de máquinas ficou incapaz para sua profissão habitual enquanto o pedreiro ficou incapaz para todo e qualquer trabalho 
Com este enquadramento, a Portaria valora o ponto em função da idade e da intensidade da ofensa corporal, sendo que o valor do ponto decresce com a idade e aumenta com a gravidade das sequelas.

Parece indiscutível que o legislador acertou, ao graduar o valor do ponto da menor à maior gravidade numa lógica multiplicativa e não apenas aditiva. Este mesmo principio está presente no valor do ponto das tabelas espanhola e italiana e nos valores arbitrados pelos tribunais franceses, o que comprova a sua universalidade

Mais discutível poderá ser a variação do ponto em função da idade, quando nos estamos a referir a direitos universais iguais para todos. Porém, se consideramos a duração do dano, como a diferença entre a idade do lesado e a sua esperança de vida, aceitar-se-á, sem dificuldade, que quem sofre por mais tempo a privação de um direito tenha de ser compensado por um valor superior ao de quem o sofre por menos. Este princípio está, aliás, explicitamente acolhido na Resolução do Conselho de Ministros do Conselho Europeu, já referida, e pode encontrar-se na lei italiana e espanhola e na prática jurisprudencial francesa, entre outras.

Nos termos da Portaria 377/2008, o dano biológico calcula-se multiplicando o número de pontos atribuído às sequelas - segundo a Tabela de Avaliação de Incapacidades Permanentes em Direito Civil, - pelo valor dos respectivos pontos, constante da tabela do Dano Biológico (anexo IV da Portaria), abaixo ilustrada (resumida) no Quadro 1.

\begin{tabular}{|c|c|c|c|c|c|c|}
\hline Pontos & $<=20$ anos & $\begin{array}{c}\text { De } 21 \text { a } 25 \\
\text { anos }\end{array}$ & $\begin{array}{c}\text { De } 26 \text { a } 30 \\
\text { anos }\end{array}$ & $\begin{array}{c}\text { De } 31 \text { a } 35 \\
\text { anos }\end{array}$ & >= 70 anos \\
\hline $1-5$ & 885 a 1040 & 830 a 1015 & 790 a 975 & 745 a 925 & $\ldots$ & 145 a 175 \\
\hline $6-10$ & 1.070 a 1.245 & 1.030 a 1.220 & 980 a 1.170 & 920 a 1.110 & $\ldots$ & 180 a 210 \\
\hline $11-15$ & 1.370 a 1.390 & 1.315 a 1.360 & 1.250 a 1.305 & 1.180 a 1.240 & $\ldots$ & 230 \\
\hline $16-20$ & 1.465 a 1.485 & 1.405 a 1.455 & 1.340 a 1.395 & 1.260 a 1.325 & $\ldots$ & 250 \\
\hline $21-25$ & 1.525 a 1.550 & 1.465 a 1.515 & 1.395 a 1.455 & 1.315 a 1.380 & $\ldots$ & 260 \\
\hline $26-30$ & 1.590 a 1.610 & 1.525 a 1.580 & 1.455 a 1.515 & 1.370 a 1.435 & $\ldots$ & 270 \\
\hline $31-35$ & 1.635 a 1.660 & 1.570 a 1.625 & 1.495 a 1.555 & 1.410 a 1.480 & $\ldots$ & 275 \\
\hline $36-40$ & 1.700 a 1.725 & 1.630 a 1.685 & 1.555 a 1.615 & 1.465 a 1.535 & $\ldots$ & 290 \\
\hline $41-45$ & 1.745 a 1.770 & 1.675 a 1.735 & 1.595 a 1.660 & 1.505 a 1.580 & $\ldots$ & 295 \\
\hline $46-50$ & 1.795 a 1.820 & 1.725 a 1.780 & 1.640 a 1.705 & 1.545 a 1.620 & $\ldots$ & 305 \\
\hline $51-55$ & 1.825 a 1.850 & 1.755 a 1.810 & 1.670 a 1.735 & 1.570 a 1.650 & $\ldots$ & 310 \\
\hline $56-60$ & 1.875 a 1.900 & 1.800 a 1.860 & 1.710 a 1.780 & 1.615 a 1.695 & $\ldots$ & 315 \\
\hline$\ldots$. & $\ldots$ & $\ldots$ & $\ldots$ & $\ldots$ & $\ldots$ & $\ldots$ \\
\hline 100 & 2.250 a 2.285 & 2.160 a 2.235 & 2.060 a 2.140 & 1.940 a 2.035 & $\ldots$ & 380 \\
\hline
\end{tabular}

\section{Quadro 1}


Por exemplo, para uma vítima de 28 anos, com uma pontuação de 38 pontos o valor do ponto varia entre 1.555 e $1.615 €$, sendo a indemnização atribuída entre $57.535 €$ e $59.755 €$. Neste caso concreto o valor médio deste intervalo parecer-nos-ia o valor razoável de indemnização atendendo a que, quer a idade, quer a pontuação, situam-se no ponto médio do intervalo.

Pode discutir-se, naturalmente, se o valor encontrando é suficiente, ou não, para reparar a perda da integridade física e psíquica. É uma questão sem possibilidade de resposta no âmbito pessoal e subjectivo. Apenas podemos encontrar respostas em termos relativos, quando comparamos os novos valores com os anteriores à Portaria ou quando os comparamos com os de outros países com os quais seja possível efectuar essa comparação.

Neste contexto, é preciso, desde logo, ter em linha de conta o Artigo $4^{\circ}$ da Portaria, relativo aos Danos Morais Complementares ${ }^{45}$. Com efeito, a norma prevê que o lesado cumule a indemnização pelo dano biológico com as indemnizações pelos seguintes danos de natureza não patrimonial:

- Por cada dia de internamento hospitalar;

- Pelo dano estético;

- Pelo quantum doloris;

- Quando resulte para o lesado uma incapacidade permanente absoluta para a prática de todo e qualquer profissão ou da sua profissão habitual

- Quando resulte para o lesado uma incapacidade permanente que lhe exija esforços acrescidos no desempenho da sua actividade profissional

- Quando o lesado, pela sua idade, não tenha entrado no mercado laboral

O legislador considerou, nestas três últimas situações, que os lesados careciam de uma protecção complementar à prevista no Anexo IV, para além da compensação devida pelos danos patrimoniais futuros nos termos já referidos. Repare-se que o legislador usa conceitos utilizados em Direito do Trabalho, na medida que o que pretende é precisamente considerar a repercussão na vida laboral como factor de agravamento ou majoração dos danos não patrimoniais.

E fê-lo, em primeiro lugar, porque estas situações estão normalmente associadas as lesões mais graves, que exigem especial protecção; em segundo, pela repercussão que a alteração na vida laboral tem no indivíduo, no seu projecto de vida e na sua realização profissional e social. Acresce que é possível encontrar no direito comparado critérios semelhantes de agravamento dos danos morais, como por exemplo no "Baremo"46 espanhol.

45 Anexo I da Portaria 377/2008

46 Tabla IV Factores de corrección de las indemnizaciones básicas por lesiones permanentes. Ley 30/1995 del 8 de Diciembre de Ordenación y Supervisión de los Seguros Privados 
A Portaria gradua os valores indemnizatórios, para os danos morais complementares, em função da idade e da valoração da incapacidade. Se a duração do dano, como medida do tempo de privação da vida laboral normal, não levanta grandes dúvidas como factor de agravamento, o grau de incapacidade pode ser discutível, nomeadamente quando não exista correlação entre a gravidade da lesão e a repercussão na vida laboral ou quando para a mesma gravidade de lesão a repercussão seja diferente. No futuro o legislador terá de equacionar se os intervalos em valores absolutos não deverão ser substituídos por valores relativos, como, por exemplo, percentagens de agravamento da indemnização pelo dano biológico em função da maior ou menor repercussão que exista na vida laboral.

Para os casos que se afastem das situações habituais, a Portaria não inibe as seguradoras de ajustar a sua proposta indemnizatória à situação específica em causa, esta deve ser, aliás, a conduta a seguir na formulação de toda e qualquer proposta razoável.

Finalmente, poder-se-ão criticar os limites dos intervalos, no que aos valores dos danos morais complementares respeita. Mais difícil será negar que a redução da capacidade profissional carece de ser tida em conta no valor indemnizatório, nomeadamente quando ela gerando esforços acrescidos não é susceptível de ser indemnizada a título de danos patrimoniais futuros.

Como se comparam os valores de indemnização da Portaria, para os danos biológicos e não patrimoniais, com os valores praticados noutros países, nas lesões mais leves?

Como se pode observar no quadro 2, para uma vítima de 45 anos de idade, com fractura simples do punho, sem repercussão na sua vida laboral, os valores resultantes da Portaria estão em linha com as indemnizações padrão praticadas em França, Espanha, Itália, Reino Unido e Irlanda.

\begin{tabular}{|c|c|c|c|c|c|}
\hline França $^{47}$ & Espanha $^{48}$ & Itália $^{49}$ & Portugal $^{50}$ & Reino Unido $^{51}$ & Irlanda $^{52}$ \\
\hline $3.750 €$ & $3.558 €$ & $5.743 €$ & $4.025 €$ & $4.000 £$ & $5.200-15.600 €$ \\
\hline
\end{tabular}

\section{Quadro 2}

47 Indemnização fixada pela Cour d'Appel de Paris: $750 €$ por ponto e 5 pontos

48 Valor ponto da Tabela III: $711,64 €$ por ponto e 5 pontos

49 Dano biológico relativo a 5 pontos de IPP: $4.318,29$. A este valor acresce mais $33 \%$ de dano moral $(1.425 €)$

50 Valor do ponto (de 630-805€) De 3.150€ até $4.025 €$

51 Guidelines for the assessment of general damages in personal injury cases. Non uncomplicated Colle’s fracture: Simple wrist fracture $£ 2.000$ - $£ 5.850$ (www.national-acident-helpline. co.uk)

52 PIAB Book of Quantum Fracture Substantially Recovered $€ 5.200-15.600 €$ 
Como se comparam os valores de indemnização da Portaria, para os danos biológicos e não patrimoniais, com os valores praticados noutros países nas lesões mais graves?

No quadro 3 apresentam-se valores de referência de Irlanda e França

\begin{tabular}{|l|c|c|c|c|}
\hline \multicolumn{1}{|c|}{ Sequela } & Pontos & Portugal $^{53}$ & Irlanda $^{54}$ & França $^{55}$ \\
\hline Tetraplegia & 95 & até $€ 328.500$ & até $€ 300.000$ & até $€ 450.000$ \\
\hline Amputação das duas mãos & 75 & até $€ 237.000$ & até $€ 190.000$ & até $€ 300.000$ \\
\hline Amputação de uma perna & 50 & até $€ 145.000$ & até $€ 136.000$ & até $€ 130.000$ \\
\hline
\end{tabular}

Quadro 3

Para comparar as indemnizações com Espanha é preciso ter em linha de conta que o "Baremo" espanhol indemniza danos não patrimoniais e patrimoniais, pelo que o comparativo tem de ser feito incluindo estes últimos.

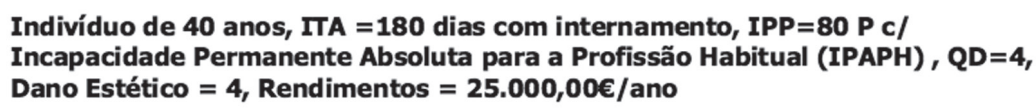

- $\quad$ ПА: $€ 12.329$

- Dano biológico: $€ 139.000$

- DM complementares: $€ 64.000$

- Dias de internamento: $€ 5.400$

- Dano Estético: $€ 7.250$

- Quantum Doloris:€ 3.200

- Dano Patrimonial Futuro: $€ 338.853$

Total: $€ 570.032$
- ITA:€5.166

- Sequelas: €204.636

- Factores de correcção:

Prejuízos económicos: $€ 24.850$

Dano Moral Complementar: $€ 86.158$

Invalidez Permanente Total: $€ 86.158$

- Danos morais de familiares: $€ 129.238$

- Dano Estético: $€ 38.696$

Total: $€ 574.902$

Aos valores anteriores acrescem, nos dois casos, as despesas de adaptação da casa e do veículo, a assistência de $3^{\mathrm{a}}$ pessoa e as despesas médicas futuras.

Pode concluir-se assim, sem margem para dúvidas, que as indemnizações que resultam da aplicação da Portaria estão razoavelmente próximas, tanto para as lesões invalidantes mais leves, como para as mais graves, das praticadas em países com níveis de rendimento bem superiores aos de Portugal.

53 Valores calculados para uma vítima jovem que não iniciou a vida laboral

54 Valores dos limites superiores definidos no Book of Quantum www.injuriesboard.ie/

55 Valores de referência utilizados pelos seguradores em França para os casos mais graves, nomeadamente as crianças 
Convém referir que estes países apresentam melhores índices de sinistralidade rodoviária grave (o que por si só já poderia implicar menores indemnizações em Portugal).

A Portaria redistribui as indemnizações em favor das lesões mais graves. Se consideramos o valor médio pago pelos danos não patrimoniais em 74 lesados, regularizados entre 2006 e $2008^{56}$, com IPP média de 81 pontos e idade média de 35 anos, o valor pago foi de 55.000€. Para a mesma idade e pontuação, a Portaria atribuiria, a "este caso tipo" , valores superiores a 200.000€.

Se analisarmos, agora, todas as vítimas com Incapacidade Parcial Permanente (IPP $)^{57}$ podemos afirmar que os valores médios atribuídos a cada ponto de IPP, pela Portaria, são superiores, excepto nos casos mais leves, aos actualmente pagos, admitida a hipótese dos valores da amostra estudada não serem díspares dos das restantes seguradoras.

\begin{tabular}{|c|c|c|c|c|c|}
\hline 597 lesados & $\begin{array}{c}\text { IPP-(0:5] } \\
\text { VM:4 }\end{array}$ & $\begin{array}{c}\text { IPP-(5:10] } \\
\text { VM:9 }\end{array}$ & $\begin{array}{c}\text { IPP-(10:20] } \\
\text { VM:16 }\end{array}$ & $\begin{array}{c}\text { IPP-(20:50] } \\
\text { VM:32 }\end{array}$ & $\begin{array}{c}\text { IPP-(50:100] } \\
\text { VM:72 }\end{array}$ \\
\hline Idade Média & 43 & 45 & 43 & 44 & 44 \\
\hline $\begin{array}{c}\text { Valor por ponto } \\
\text { paga em 2007 }\end{array}$ & $€ 1.059$ & $€ 880$ & $€ 823$ & $€ 667$ & $€ 769$ \\
\hline $\begin{array}{c}\text { Valor Ponto na } \\
\text { Portaria }\end{array}$ & $€ 630-805$ & $€ 780-965$ & $€ 1.065-1.150$ & $€ 1.195-1.282$ & $€ 1.455-1570$ \\
\hline
\end{tabular}

\section{Quadro 4}

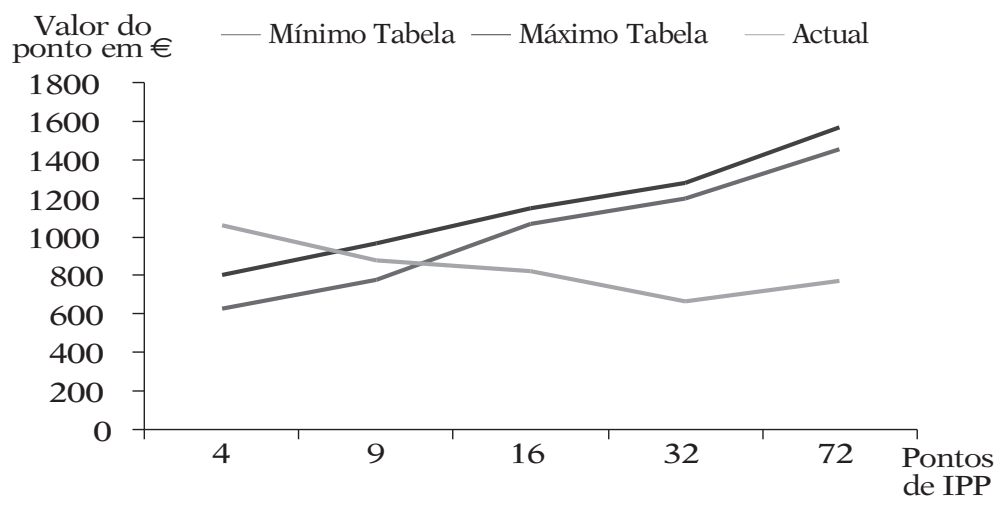

\section{Gráfico 6}

56 Grandes inválidos indemnizados pela Império-Bonança

57 Vitimas com IPP indemnizadas em 2007 pela Império-Bonança 
Donde se concluir que o legislador, claramente, procurou redistribuir as indemnizações em benefício das situações mais graves - mortes e incapacidades elevadas - sendo nestas últimas onde se verificam as maiores disparidades face a valores praticados noutros países europeus, seguindo, assim, a mesma lógica de outras reformas do sistema indemnizatório por acidentes viação ${ }^{58}$.

Para concluir o capítulo relativo aos Outros Danos Morais Complementares, é preciso mencionar as indemnizações previstas na Portaria para os seguintes danos:

- Pelos dias de internamento hospitalar, de 20 a $30 € /$ dia

- Pelo dano estético, de 800 a $10.000 €$, numa tabela de 1 a 7 graus

- Pelo quantum doloris, isto é pela dor sofrida antes da alta clínica, de 800 a $5.200 €$, numa escala de 1 a 7 , sendo que os valores tabelados começam no grau 4

Criticamente, é de admitir que a opção do legislador de não incluir valores de indemnização pelos danos morais para os dias de incapacidade sem internamento ou para o quantum doloris em grau 1,2 ou 3 possa ser polémico.

Contudo, a este respeito, dir-se-à que o legislador está a aplicar, strictu sensu, o número 1 do artigo $496^{\circ}$ do Código Civil, no qual se refere: "na fixação da indemnização deve atender-se aos danos não patrimoniais que, pela sua gravidade merecem a tutela de direito".

Em todo o caso, convém mencionar que o facto da Portaria não obrigar a seguradora a incluir na sua proposta razoável um valor para indemnizar estes danos, tal não implica que ela não deva indemnizá-los quando, pela sua natureza e/ou gravidade, o mereçam, como acontecerá, por exemplo, nas situações de internamento domiciliário prolongado ou quando os tratamentos clínicos tenham comportado incómodos significativos para os lesado.

O mesmo se aplica a danos menos habituais que a Portaria não contempla de forma expressa. Temos, a este respeito, como exemplos, o prejuízo de afirmação pessoal e o prejuízo sexual que, a verificarem-se, terão, necessariamente, de ser indemnizados segundo princípios de equidade e, sempre que possível, em linha com os critérios nela previstos para a indemnização dos outros danos não patrimoniais.

58 Elucidativo desta tendência é a avaliação da necessidade da reforma do sistema de compensação no Quebec. "The main weaknesses in the liability (or fault) system with a single and definitive payment scheme concerned bodily injuries in which minor lesions were over-compensated, although extensive bodily injury were notoriously under-compensated" Jean-Lous Gauvin. A Centralized Approach to Compensation, Qubec. PartnerRe 2008. Bodily Injury Viewpoints for Europe 


\section{Conclusões}

A primeira conclusão que importa retirar é a de que os valores e critérios que configuram a Proposta Razoável aproximam as indemnizações do seguro obrigatório português às vigentes noutros países europeus.

A segunda, é a de que o modelo indemnizatório está em linha com a legislação e/ou a prática jurisprudencial da maioria dos países europeus, no sentido de existir uma clara separação entre os danos patrimoniais, calculados caso a caso, e os danos biológicos e não patrimoniais, calculados em função de valores de referência que permitem indemnizar de forma igual o que é igual - princípio de igualdade - e de forma diferente o que é diferente - principio de diversidade ${ }^{59}$. ultrapassando a actual situação, sem igual na Europa, de indemnizar danos de natureza não patrimonial em função dos rendimentos auferidos.

A terceira é a de o modelo indemnizatório redistribui as indemnizações em favor dos lesados mais graves, atribuindo valores mais elevados às vitimas com lesões mais graves, nomeadamente quando estão impedidas de desenvolver o seu trabalho habitual ou qualquer outro tipo de trabalho. Acresce que os Tribunais mantêm o poder discricionário de alterar os valores da proposta razoável, se esta não se adequar à situação concreta do lesado a indemnizar.

A quarta conclusão, a terminar, é a que o novo sistema estabelece uma relação de total transparência entre as seguradoras e os lesados, favorecendo, naturalmente, os mais desprotegidos. Como um exemplo vale mais do que mil palavras, permitimo-nos reproduzir um e-mail enviado por um advogado na sequência de uma proposta razoável efectuada muito recentemente ${ }^{60}$.

Após ter regularizado junto da sua respeitada Companhia o sinistro automóvel (...) pensei em escrever algo sobre a forma como (...) conduziram o processo até à sua conclusão. (...) Desta vez não deixei cair no esquecimento, porque é simultaneamente um gosto e uma obrigação agradecer-lhe (... ) pela forma transparente e honesta como conduziram a regularização do sinistro em apreço, ademais porque não é habitual (pelo menos nunca me aconteceu) não ser aceite a minha proposta para regularização do sinistro porque aquém do valor que a Companhia tinha para pagar em sede de regularização extrajudicial. Esta postura é algo que não poderei esquecer (....!

Por último e não menos importante, reter que o novo normativo revaloriza a função do médico avaliador na formulação da proposta razoável. A actual legislação dá, à seguradora, a faculdade de pedir ao lesado para ser avaliado

59 AVV. Marco Bona Public Hearing on Road Traffic Accidents en the European Parliament. Committee on Legal Affairs. 19 March 2007

60 E-mail enviado pelo Senhor Dr. A. Dinis de Oliveira em 11 de Novembro de 2008. A reprodução foi autorizada pelo autor. Sublinhado pelos autores 
por perito médico. O lesado, por sua vez, tem o direito a receber o relatório pericial, em prazo não superior a dez dias após estar na posse da seguradora.

O perito médico passa, sem dúvida, a ser o principal interlocutor da vítima na procura de alternativas adequadas à reparação dos danos que sofreu e, sempre que se justifique, à sua reabilitação e integração na vida activa.

Terminamos sabendo que, o sistema de compensação das vítimas de acidentes de viação, agora delineado, não é perfeito, nem podia sê-lo. Abre, porém, novas vias que ajudam a ultrapassar as dificuldades sentidas, no dia a dia, por todos os que têm responsabilidade em indemnizar. Novas vias que, beneficiando da rica e vasta experiência jurisprudencial existente, nos aproxima das melhores práticas europeias. É responsabilidade de todos, seguradoras, advogados, peritos médicos e, naturalmente, dos tribunais, como supervisores de ultima instância, aperfeiçoá-lo. E o primeiro passo neste fim pode ser institucionalizar um centro de arbitragem que, mediante parecer do Instituto Nacional de Medicina Legal, seja competente para resolver os conflitos entre as partes relativamente à avaliação do dano corporal, segundo a proposta formulada pelo Conselheiro Sousa Dinis ${ }^{61}$.

\section{Bibliografia}

ALVAREZ QUINTERO J.M. Delinquência Rodoviária, impunidade e compensação de danos. Coimbra. Revista Portuguesa do Dano Corporal n 142004

ÁLVARO DIAS J.A Dano Corporal Quadro epistemológico e aspectos ressarcitórios. Coimbra. Almedina 2001

BRAGA A. A repração do Dano Corporal na Responsabilidade Civil Extracontractual. Coimbra. Almedina 2005

COMITÉ EUROPÉEN DES ASSURANCES. L'indemnisation du dommage corporel en Europe. Essai Comparatif www.cea.assur.org 2004

DA COSTA OLIVEIRA A.F. Seguro obrigatório de Responsabilidade Civil Automóvel. Síntese das alterações de 2007-DL 291/2007,21 de Agosto. Coimbra. Almedina 2008

DONÁRIO A.A. Análise Económica da Regulação Social. Causas, Consequências e Politicas dos Acidentes de Viação.Ediual 2007

NUNO VIEIRA, D Aspectos práticos da avaliação do dano corporal em Direito Civil. Coimbra. Biblioteca Seguros da Caixa Seguros. 2008

PARTNER RE Bodily Injury. Viewpoint for Europe. www.partenerre.com

FUNDACION INADE Sistema para la Valoración de los Daños y Perjuicios causados a las personas en accidentes de circulación 2008 www.inade.org

SOUSA DINIS J.J. A baremização do dano corporal na responsabilidade civil (excluídos os acidentes laborais) Coimbra. Revista Portuguesa do Dano Corporal n 142004

${ }^{61}$ SOUSA DINIS J.J. A baremização do dano corporal na responsabilidade civil (excluídos os acidentes laborais) Coimbra. Revista Portuguesa do Dano Corporal n 142004 
Resumo: A actualização do sistema de indemnização nos acidentes viação. Uma reforma necessária?

A compensação de danos corporais em Portugal foi alterada recentemente. Os autores defendem que as novas disposições são necessárias e oportunas, e conduzem a uma compensação das vítimas mais transparente, célere e justa.

Um dos principais méritos do novo sistema é o de reequilibrar as indemnizações, beneficiando os que sofrem lesões mais graves e os que têm menores recursos financeiros. 0 novo normativo está mais ajustado à resolução (75) 7 aprovada pelo Comité de Ministros do Conselho Europeu.

Finalmente, os autores consideram que Portugal está a superar o atraso histórico que tinha na adaptação da legislação do seguro obrigatório às necessidades das vítimas.

Palavra-chave: Proposta razoável.

Summary: To update the road compensation system. Is it necessary?

New provisions regarding personal damage compensation have come into force in Portugal. The authors believe these new regulations were necessary and opportune, leading a more transparent, faster and fairer compensation to the victims.

One of the main features of the new system is a re-balanced award beneficing the worse after-effects and people with fewer financial resources. Also the current provisions fit better the (75) 7 resolution approved by the Committee of Ministers of the European Council.

Finally the authors consider Portugal is overcoming its age-old problem of delay in adopting compulsory motor insurance for victim's needs.

Key-word: Reasoned offer.

Résumé: L'actualisation du système d'indemnisation des victimes d'accidents de la circulation. Une réforme nécessaire?

De nouvelles conditions d'indemnisation des dommages corporels sont entrées en vigueur au Portugal. Les auteurs estiment que ces réglementations étaient nécessaires et opportunes, conduisant à une compensation des victimes plus transparente, plus rapide et plus juste.

L'une des principales caractéristiques de ce nouveau système est un rééquilibrage de l'indemnité dans les cas de séquelles les plus graves et des personnes aux faibles revenus. De même, les dispositions actuelles répondent mieux aux critères de la résolution 7 (75) approuvée par le Comité des Ministres du Conseil de l'Europe.

Pour conclure, les auteurs considèrent que le Portugal est en train de rattraper son retard historique en adoptant une assurance automobile obligatoire qui répond aux besoins des victimes.

Mot-clé: Offre raisonnable.

\section{Pedido de separatas:}

JOSÉ ALVAREZ QUINTERO

jose.quintero@bep.pt 